\title{
SUSTAINABLE WATER RESOURCES MANAGEMENT FOR IRRIGATED AGRICULTURE IN LATIN AMERICA
}

\author{
Max Billib ${ }^{1}$, Eduardo A. Holzapfel ${ }^{2}$, and Alicia Fernández-Cirelli ${ }^{3}$
}

\section{INTRODUCTION}

World population will be near nine thousand million inhabitants by 2050 . Considering the growing pressure on finite freshwater and soil resources, it becomes clear that the challenge of feeding tomorrow's world population is, to a large extent, about improved water productivity within present land use. Meanwhile water requirements for different purposes will increase, so all efforts focused on a rational use of water will be indispensable. Ninetyfive per cent of current population growth occurs in developing countries and a significant proportion of these people still depend on a predominantly rain-fed-based rural economy.

Agriculture is by far the largest water-use sector, accounting for about $70 \%$ of all water withdrawn worldwide from rivers and aquifers for agricultural, domestic and industrial purposes. In several developing countries irrigation represents up to $95 \%$ of all water withdrawn, and it plays a major role in food production and food security (Comprehensive Assessment of Water Management in Agriculture, 2007).

In the arid and semiarid climates, irrigation is often essential to achieve economically viable crop productions. Benefits from irrigation may be partially offset by detrimental effects of rising water tables and soil salinization, inefficient water delivery systems and poor on-farm irrigation techniques.

In the absence of sufficient canal water supplies, infrastructure and a well-designed and effective monitoring and communication system, moving towards the on-demand system will be unproductive. For the long term sustainability of the irrigation system, improvements in the performance of the present water allocations and on-farm water management practices seems to be more necessary as any other practice (Sarwar et al., 2001).

'Leibniz Universität Hannover,Institute of Water Resources Management, Hydrology and Agricultural Hydraulic Engineering, Appelstr. 9 a, D-30167 Hannover, Germany (billib@iww.uni-hannover.de).

${ }^{2}$ Universidad de Concepción, Facultad de Ingeniería Agrícola, Av. Vicente Méndez 595, Chillán, Chile (eholzapf@udec.cl).

${ }^{3}$ Universidad de Buenos Aires, Facultad de Ciencias Veterinarias, Centro de Estudios Transdisciplinarios del Agua, Av. Chorroarin 280, Ciudad Autónoma de Buenos Aires, Argentina (afcirrelli@fvet.uba.ar).
The agricultural development strategies of most of the African, European and American countries depend on the possibility of maintaining, improving and expanding irrigated agriculture (Siebert et al., 2006). However, as the pressure on water resources increases, irrigation is facing growing competition from other water-use sectors and is becoming a threat to the environment in an increasing number of regions. Intensification of agricultural activities under arid or semiarid conditions involves irrigation, fertilization and organic additives, applied in varying amounts to the annual cropped and orchards areas.

In such scenario, the efficient use of water in agriculture is a main concern worldwide. Irrigation management should focus in the adoption of practices that enhance the efficient use of water so that other sectors can have more water for economic use. At the same time, it is equally important to develop watershed or irrigation systems water management policies that enable irrigation managers or planners to optimally manage scarce available water resources and maintain under sustainable condition the agricultural production processes (Sarwar $e t$ al., 2001).

A comprehensive, complete, and quantitatively defined problem analysis, including alternative strategies for solving problems, can be defined and evaluated. Definite solutions to all these problems are impossible to realize solely at the farm level. Regional or watershed solutions have to be found that are based on an integrated approach to ground- and surface-water management along with improved on-farm water management and operation of the irrigation systems (Kumar and Singh, 2003). Diagnosis in water management is being supported more recently with the help of mathematical models simulating the various processes involved and their interactions in the system.

A change from a natural habitat to intensive agricultural practices leads to increased leachates production and pollution risks. Non-point source pollution from nutrient and pesticide application has the potential to degrade water resources (Troiano et al., 1993). It is imperative that the impact of farming practices and proposed best management practices on water quality be evaluated so that appropriate practices can be developed to minimize pollution. 
On the other hand, recent public awareness of the scarcity of water for food production has prompted sustainable agricultural development issues in irrigation water management. Under conditions of scarcity and conflicts concerning irrigation water use and management, it is required that it must be distributed as efficiently as possible, to ensure satisfactory production and low cost. For the incorporation of the corresponding environmental indices in the decision-making process, the definition and trade-offs between the criteria examined must be clearly established. Conway (1975), one of the leading researchers in this type of topic, defined sustainability "as the ability of a system to withstand collapse while maintaining satisfactory production". In Conway's terms, except for equability, agricultural systems should be assessed according to productivity, stability, and sustainability in association with yield and income distribution (Manoliadis, 2001). It has been shown that environmental indices expressing sustainability-related criteria of irrigation management under sustainable development can be obtained during irrigation monitoring from randomly collected data. The study of Manoliadis (2001) indicated that environmental indices could also be incorporated to select alternative irrigation policies for irrigation water allocation.

All these issues call for the implementation of sustainable irrigation in order to preserve the environment while keeping the actual levels of food production. On this regard, Oster and Wichelns (2003) defined sustainability as the likelihood that an irrigation system will continue to generate desirable outputs and amenities at reasonable costs in future. They pointed out that in order to reach sustainability, irrigation and drainage systems should be managed in a manner that does not degrade the quality of land, water, and other natural resources that contribute to agricultural production and environmental quality.

The most serious risks to surface water and aquifers is a worldwide problem and great effort is directed to study the rate of recharge and the measures required to minimize the loads of contaminants seeping from agricultural areas toward the aquifers. Little data is available on the distributions of solute concentrations with depth for different fields, especially for irrigated land under semiarid and arid conditions, where the pollution of aquifer can drive to serious consequences that are not wished.

Socio-economic pressures for increased agricultural production are in conflict with preservation of the environment and resources. Common irrigation practices require application of water amounts in excess of the crop's needs in order to minimize soil salinization. Moreover, rain falls (rain fed farming) and irrigation applications come in pulses, which are out of phase with respect to the crop's water uptake rates. Thus, allowing some of the added water and soil solution to redistribute itself and be leached out below the active root zone. The leachates loads and amounts of water seepage depend on the temporal and spatial distribution of active roots and their uptake rates as compared to supply rates and can be minimized, provided fertilizers and water uptake efficacies of a crop are maximized, and are in phase with water and nutrients supply rates and application timing.

The more intensive and productive the practice is, the more distinct these trends become. There exist optimal fertilizer/irrigation regimes which combine high yields, minimal leachates production and reduced pollution risks; and such combinations are site, weather, crop-sequence and agronomic-practice dependent (Hadas et al., 1999). It is highly probable that there are no single, direct information-transfer functions available for dealing with intensive agricultural practices, combined with reduced pollution risks. Each must be tested before its application is implemented considering the irrigation systems and managements as well as the chemicals applied.

The purpose of this special issue is to analyze the state of the art of a sustainable water management for irrigated agriculture in Latin America, taking into account the particular characteristics of the soil-plant-atmosphere system in those regions as well as social, environmental, energy and economical factors.

\section{ACKNOWLEDGEMENTS}

The papers of this special issue are the result of the multilateral Project "Knowledge Assessment on Sustainable Water Resources Management for Irrigation" (KASWARMI) INCO $\mathrm{N}^{\circ}$ 043513, financed by the Commission of the European Communities in the framework of the $6^{\text {th }}$ Research Program. The KASWARMI research group consisted of three European partners: Germany, Leibniz Universität Hannover; Hungary, St. Istvan University Gödöllö; Spain, Universidad de Córdoba; and six Latin American partners: Argentina, Universidad de Buenos Aires and Instituto Argentino de Investigaciones de las Zonas Áridas at Mendoza; Bolivia, Universidad Mayor de San Simón at Cochabamba; Brazil, Universidad Federal de Campina Grande-Paraíba and Universidad Federal do Recôncavo da Bahia; Chile, Universidad de Concepción; and the general coordination was by the Leibniz Universität Hannover team and for the South American countries by the Universidad de Concepción team. The international consortium was focused on an interdisciplinary approach including the disciplines of agricultural engineering, agronomy, soil science, hydrology, water resources management, systems engineering, economy, and social sciences. 


\section{LITERATURE CITED}

Comprehensive Assessment of Water Management in Agriculture. 2007. Water for food, water for life: A comprehensive assessment of water management in agriculture. 645 p. London, UK: Earthscan, and Colombo, Sri Lanka: International Water Management Institute.

Conway, G.R. 1975. The properties of agro-ecosystems. Agric. Syst. 24:95-98.

Hadas, A., A. Hadas, B. Sagiv, and N. Haruvy. 1999. Agricultural practices, soil fertility management modes and resultant nitrogen leaching rates under semi-arid conditions. Agric. Water Manage. 42:81-95.

Kumar,R., and J. Singh.2003. Regional water management modelling for decision support in irrigated agriculture. J. Irrig. Drain. E-ASCE 129:432-439.

Manoliadis, O. 2001. Analysis of irrigation systems using sustainability-related criteria. J. Environ. Qual. 30:1150-1153.

Oster, J.D., and D. Wichelns. 2003. Economic and agronomic strategies to achieve sustainable irrigation. Irrig. Sci. 22:107-120.
Sarwar, A., W.G.M. Bastiaanssen, and R.A. Feddes. 2001. Irrigation water distribution and long-term effects on crop and environment. Agric. Water Manage. 50:125140.

Siebert, S., J. Hoogeveen, and K. Frenken. 2006. Irrigation in Africa, Europe and Latin America. Update of the digital global map of irrigation areas to Version 4. Frankfurt Hydrology Paper 05. 135 p. University of Frankfurt, Institute of Physical Geography, Frankfurt am Main, Germany. Available at http://www.geo. uni-frankfurt.de/ipg/ag/dl/f_publikationen/2006/ FHP_05_Siebert_et_al_2006.pdf

Troiano, I., C. Garretson, C. Krauter, I. Brownell, and J. Huston. 1993. Influence of amount and method of irrigation water application on leaching of atrazine. J. Environ. Qual. 22:290-298. 